Short Communication

\title{
Lisinopril reverses behavioural alterations in spontaneously hypertensive rats
}

\author{
Kristina Repova $^{1 *}$, Silvia Aziriova ${ }^{1 *}$, Dominika Kovacova ${ }^{1}$, Simona Trubacova $^{1}$, Tomas Baka $^{1}$, \\ Romana Kanska ${ }^{1}$, Andrej Barta ${ }^{2}$, Peter Stanko ${ }^{1}$, Stefan Zorad ${ }^{3}$, Lubos Molcan ${ }^{4}$, Michaela \\ Adamcova $^{5}$, Ludovit Paulis ${ }^{1,2}$ and Fedor Simko ${ }^{1,3,6}$ \\ ${ }^{1}$ Institute of Pathophysiology, Faculty of Medicine, Comenius University, Bratislava, Slovakia \\ ${ }^{2}$ Institute of Normal and Pathological Physiology, Center for Experimental Medicine, Slovak Academy of Sciences, Bratislava, \\ Slovakia \\ ${ }^{3}$ Institute of Experimental Endocrinology, Biomedical Research Center, Slovak Academy of Sciences, Bratislava, Slovakia \\ ${ }^{4}$ Department of Animal Physiology and Ethology, Faculty of Natural Science, Comenius University, Bratislava, Slovakia \\ ${ }^{5}$ Department of Physiology, Faculty of Medicine, Charles University, Hradec Kralove, Czech Republic \\ ${ }^{6} 3^{\text {rd }}$ Department of Internal Medicine, Faculty of Medicine, Comenius University, Bratislava, Slovakia
}

\begin{abstract}
This study investigated the effect of lisinopril (angiotensin-converting enzyme inhibitor) on potential behavioural alterations in spontaneously hypertensive rats (SHR). Three groups of 15-17-week-old rats were investigated for 2 weeks: Wistar control group, SHR group and SHR+lisinopril group. Systolic blood pressure (SBP) was normal in Wistar rats, SHR expressed hypertension and lisinopril normalized the SBP. We observed increased time spent in and increased frequency of entries to the central area of the open field in SHR, while lisinopril induced a trend to reduce the time spent in the central area of the open field and reduced the frequency of entries there. There was a positive correlation between SBP and reduced anxiety-like behaviour in normotensive rats; no correlations in the SHR or SHR+lisinopril groups were observed. We conclude that lisinopril normalized the increase in SBP and partly reversed the alterations of anxiety-like behaviour in SHR.
\end{abstract}

Key words: Lisinopril — Behaviour — Spontaneously hypertensive rats - Hypertension — Anxiety

Experimental cardiovascular pathologies are associated with different neuropsychiatric symptoms, while on the contrary, various mental disorders may support the progression of cardiovascular, neurohumoral or metabolic disorders (Pechanova et al. 2006; Bernatova et al. 2010; Puzserova et al. 2012; Aziriova et al. 2016; Olexova et al. 2016; Pokusa et al. 2016; Senko et al. 2017; Repova et al. 2018). In a clinical setting, patients with cardiac diseases suffer from post-traumatic stress disorder (Vilchinsky et al. 2017), yet mental disorders not only impair their adherence to therapeutic management (Gentil et al. 2017); they can also contribute to the progres-

\footnotetext{
* These authors contributed equally to this work.

Correspondence to: Fedor Simko, Institute of Pathophysiology, Faculty of Medicine, Comenius University, Sasinkova 4, 81108 Bratislava, Slovakia

E-mail: fedor.simko@fmed.uniba.sk
}

sion of cardiovascular diseases (Shields and Slavich 2017). Since hypertension is among the most frequent cardiovascular pathologies, the study of the relationship between hypertension and anxiety is a challenging issue.

Spontaneously hypertensive rats (SHR) were shown to display a number of behavioural abnormalities such as increased locomotor activity, particularly during preadolescence, inattention, or impulsivity; thus resembling the major symptoms of attention deficit hyperactivity disorder (Mc Fie et al. 2012). Some authors suggested using SHR as a model of schizophrenia due to the observed hyperlocomotion, social interaction deficit and diminished contextual fear conditioning (Peres et al. 2018).

Inhibiting angiotensin II (Ang II) production or its effect is one of the most effective therapeutic approaches in cardiovascular medicine (Simko and Simko 1999; Simko et al. 2003; Paulis et al. 2016). Interestingly, a number of experi- 
mental and clinical studies have indicated that angiotensin converting enzyme (ACE) inhibitors can modify behavioural manifestations in experimental animals and humans. An anxiolytic effect has been observed in doxorubicin-treated rats that were administered captopril (Aziriova et al. 2014) and in renal-hypertensive rats that were administered enalapril (Srinivasan et al. 2003). Enalapril, captopril and lisinopril attenuated both anxiety and depression in hypertensive patients (Germain and Chouinard 1989; Braszko et al. 2003, Hertzman et al. 2005).

The aim of our study was to determine if the potential behavioural alterations in SHR could be reversed by the ACE inhibitor, lisinopril.

Adult (15-17-week-old: $250 \mathrm{~g}$ for SHR and $350 \mathrm{~g}$ for Wistar) male rats (Department of Toxicology and Laboratory Animals Breeding, Dobra Voda, Slovakia) were randomly divided into three groups ( $n=6$ per group) as follows: control Wistar rats, SHR and SHR treated with lisinopril $(1 \mathrm{mg} / \mathrm{kg} /$ day, Sigma-Aldrich, Bratislava, Slovakia; SHR+LIS). Lisinopril was administered via osmotic minipumps 2ML4 (DURECT Corporation, Cupertino, California, USA). The osmotic minipumps were implanted intraperitoneally and delivered solutions continuously for two weeks of the experiment (pumping rate: $60 \mu \mathrm{l} / 24 \mathrm{~h}$ ). The control and SHR groups received physiological saline only (sodium chloride $0.9 \%$ w/v i.v. Infusion Bieffe sol inf, Bieffe Medital S.p.A., Grosotto, Italy) in a total volume of $2 \mathrm{ml}$ per osmotic pump. The SHR+LIS group received lisinopril dissolved in physiological saline $(1 \mathrm{mg} / \mathrm{kg} /$ day) in a total volume of $2 \mathrm{ml}$ per osmotic pump.

The rats were housed in individual cages with a controlled environment of $12 \mathrm{~h} / 12 \mathrm{~h}$ light/dark rhythm, $150 \mathrm{~lx}$ light intensity, $21 \pm 2^{\circ} \mathrm{C}$ temperature, $55 \pm 10 \%$ humidity and fed a regular pellet diet ad libitum. The investigation complied

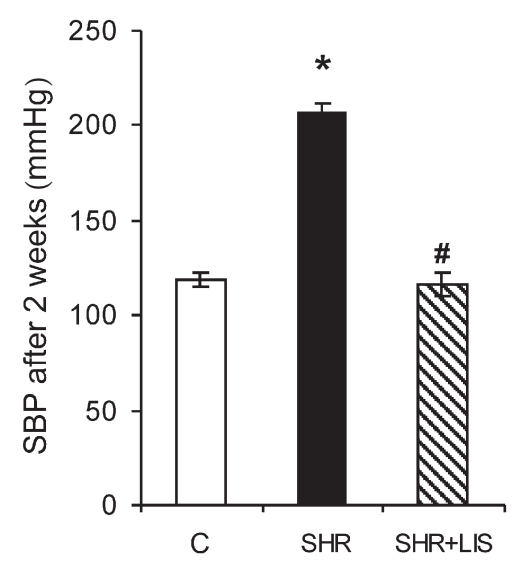

Figure 1. The effect of lisinopril on systolic blood pressure (SBP) after two weeks of treatment of spontaneously hypertensive rats. C, Wistar controls; SHR, spontaneously hypertensive rats; SHR+LIS, spontaneously hypertensive rats treated by lisinopril. ${ }^{\star} p<0.05 v s$. C, \# $p<0.05$ vs. SHR. with the Guide for the Care and Use of Laboratory Animals published by the US National Institutes of Health (NIH, Bethesda, MD, revised 2011). The experiment was approved by the Ethical committee of the Institute of Pathophysiology, Faculty of Medicine, Comenius University, Bratislava, Slovak Republic (approval number: 1347/14-221). Systolic blood pressure (SBP) was measured by non-invasive tailcuff plethysmography after two weeks of treatment. During measurements, the rats were placed in a tunnel-like box, and showed no signs of stress.

After two weeks of treatment, the anxiety-like behaviour was assessed using a battery of tests in the following order: open field (OF), elevated plus maze (EPM), and light/dark box (LDB). The time spent in and the frequency of entries to the central part of the OF; the time spent in and the frequency of entries to open arms of the EPM; and the time spent in and the frequency of entries to the light area of the LDB were assessed as parameters of the reduced anxiety-like behaviour. After each animal was measured in the corresponding test, the apparatus was cleaned with $60 \%$ ethanol to remove olfactory cues. Behavioural analysis was performed using Ethovision XT 10 tracking software (Noldus, Wageningen, the Netherlands). All procedures of the behavioural testing were performed according to Krajcirovicova et al. (2018).

The results are expressed as mean \pm S.E.M. Differences were significant if the $p$-value was less than 0.05 . The Shapiro-Wilk test was used to detect the normal distribution of data. For statistical analyses, a one-way analysis of variance (ANOVA) with a LSD post hoc test was used in the normally distributed data. The Pearson correlation was used to indicate the relationship of SBP with the parameters of anxiety-like behaviour in normally distributed data.

After two weeks of treatment, systolic blood pressure was $118.7 \pm 4 \mathrm{mmHg}$ in the control group and SHR showed hypertension with the SBP $206.4 \pm 4.7 \mathrm{mmHg}(p=0.0001)$. Lisinopril decreased the SBP of the SHR $(114.8 \pm 7.4 \mathrm{mmHg}$; $p=0.0001)\left(\mathrm{F}_{(2,16)}=69.343 ; p=0.0001\right)$ (Figure 1$)$.

After two weeks of treatment, the percentage of time spent in the central area of the OF by the control group was $1.4 \pm 0.6 \%$ and was increased among the SHR (10.5 \pm $2.6 \% ; p=0.001)$; lisinopril induced a trend to decrease it $(6.3 \pm 0.9 \% ; p=0.089)\left(\mathrm{F}_{(2,16)}=8.630 ; p=0.003\right)$ (Figure $2 \mathrm{~A})$. The frequency of entries to the central area of the $\mathrm{OF}$ by the control group was $2.3 \pm 1.1$. There was a significant increase among the SHR $(8.8 \pm 1.0 ; p=0.001)$; lisinopril significantly reduced it $(5.0 \pm 1.1 ; p=0.025)\left(\mathrm{F}_{(2,16)}=9.557\right.$; $p=0.002$ ) (Figure $2 \mathrm{~B}$ ). The percentage of time spent in the open arms of the EPM by the control group after two weeks of treatment was $28.1 \pm 6.8 \%$ and there was no significant difference between groups $\left(\mathrm{F}_{(2,16)}=0.057 ; p=0.944\right)$ (Figure $2 \mathrm{C})$. The frequency of entries to the open arms of the EPM by the control group was $5.9 \pm 1.4$ and there was no significant difference between groups $\left(\mathrm{F}_{(2,16)}=0.261 ; p=0.773\right)$ (Figure 
A

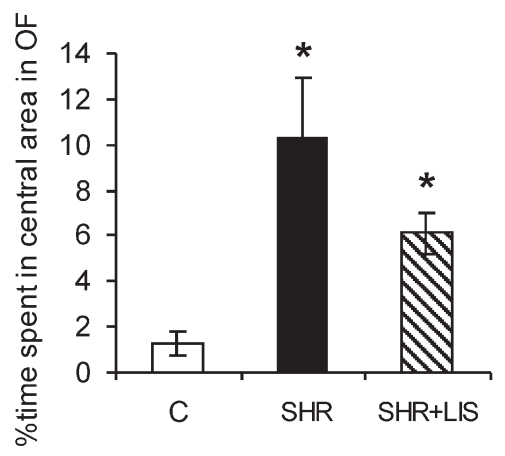

C

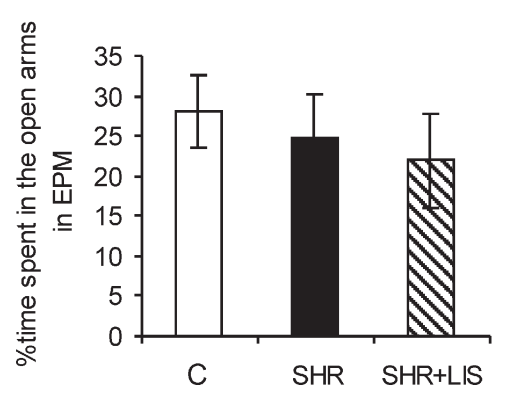

E

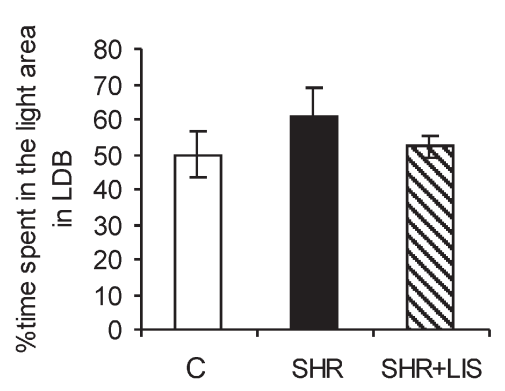

B

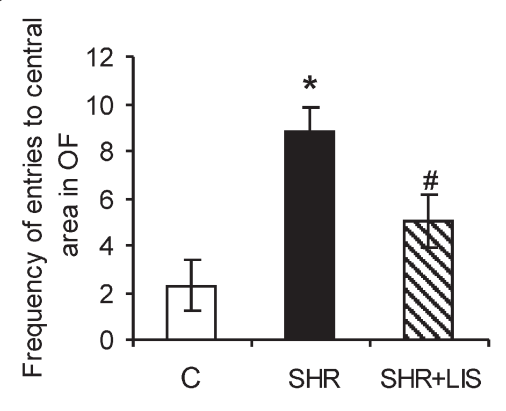

D

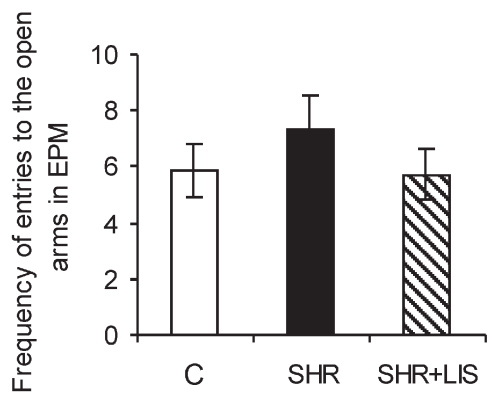

$\mathrm{F}$

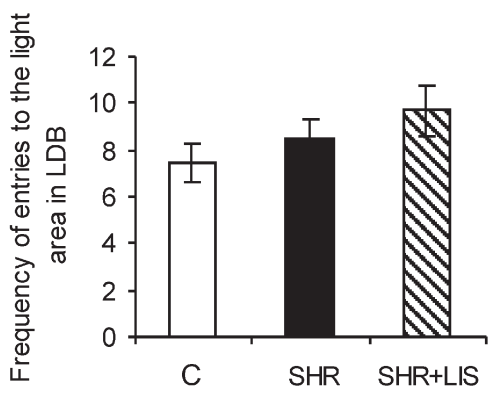

Figure 2. The effect of lisinopril on anxiety-like behaviour among spontaneously hypertensive rats. A. The percentage of time spent in the central area of the open field (OF). B. The frequency of entries to the central area of the OF. C. The percentage of time spent in the open arms of the elevated plus maze (EPM). D. The frequency of entries to the open arms of the EPM. E. The percentage of time spent in the light area of the light-dark box (LDB). F. The frequency of entries to the light area of the LDB. C, Wistar controls; SHR, spontaneously hypertensive rats; SHR+LIS, spontaneously hypertensive rats treated by lisinopril. ${ }^{*} p<0.05 v$ s. C, $\# p<$ 0.05 vs. SHR.
2D). The percentage of time spent in the light area of LDB by the control group after two weeks of treatment was $49.9 \pm$ $9.7 \%$ and there was no significant difference between groups $\left(\mathrm{F}_{(2,16)}=0.502 ; p=0.615\right)$ (Figure 2E). The frequency of the entries to the light area of LDB by the control group was 7.4 \pm 1.3 , and there was no significant difference between groups $\left(\mathrm{F}_{(2,16)}=1.313 ; p=0.297\right)$ (Figure $\left.2 \mathrm{~F}\right)$.

There was a positive correlation between SBP and time spent in the centre of the OF by the control group ( $r=0.858$; $p=0.014$ ); no correlations in the SHR or SHR+LIS groups were observed (Figure 3).

SHR, a model of genetically determined enhancement of blood pressure (BP), resembles essential hypertension in humans, resulting in heart and peripheral organ alterations (Simko et al. 2009). Remarkably, SHR were also shown to manifest a number of behavioural modifications mimicking human schizophrenia symptoms, represented by positive or negative symptoms, and cognitive and information processing deficits (Peres et al. 2018). Moreover, SHR have been used as a model of attention deficit/hyperactivity disorder (Kishikawa et al. 2014) with less anxiety behaviour (Tsai et al. 2017).

In our experiment, reduced level of anxiety among the SHR was observed in terms of increased time spent in the central area of the OF and increased frequency of entries there. These data are in agreement with the findings of other authors when the SHR showed reduced level of anxiety in OF and EPM compared to the controls (Howells et al. 2009). The reduced level of normal anxiety in SHR seems to be associated with increased impulsivity and locomotion activity (Howels et al. 2009; Garcia and Kirkpatrick 2013). These behavioural traits are present even before the SHRs develop hypertension and remain stable during adulthood (Adriani et al. 2003). Although no significant behavioural changes in 
A

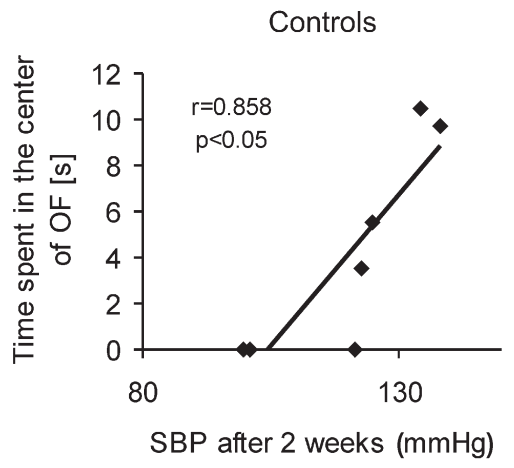

B

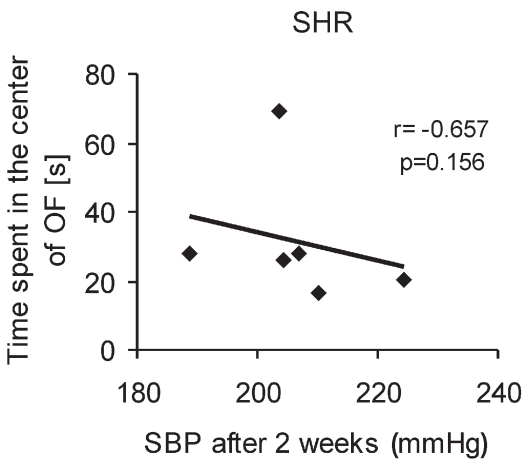

C

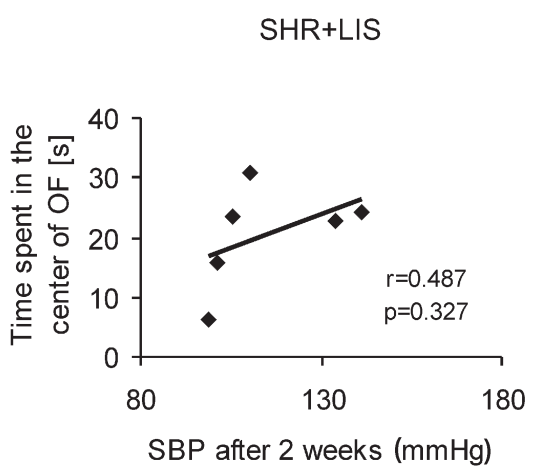

Figure 3. Correlations between systolic blood pressure (SBP) after two weeks of treatment with parameters of anxiety-like behaviour in controls (A), in spontaneously hypertensive rats (SHR) (B) and in SHR treated by lisinopril (SHR+LIS) (C). r, Pearson correlation coefficient; OF, open field.

EPM or LDB were observed in the SHR in our experiment, the numerical increase of both the frequency of entries to the open arms in the EPM and the percentage of time spent in the light area of the LDB might be expected to achieve significant difference if the number of rats in the corresponding groups were higher. Moreover, the behavioural manifestations among the SHR may be influenced by various factors such as peripubertal exposure to environmental enrichment (Santos et al. 2016), housing-style (Tsai et al. 2017), age and gender of the SHR (Hendley et al. 1985).

In this experiment, the reduced level of anxiety observed in the SHR was partly reversed by lisinopril. Furthermore, there was a positive correlation between the SBP and decreased anxiety-like behaviour of normotensive rats; however, no significant correlation in SHR and SHR+LIS groups was observed. In fact, the lack of correlation between SBP and anxiety-like behaviour in the SHR and SHR+LIS supports the view that the behavioural modifications in these groups are not related to the hemodynamic changes. In SHR, they seem to be associated with neurohumoral activation - hyperfunctional noradrenergic system (Howells et al. 2012) similar to humans with essential hypertension (Goldstein 1983). In SHR+LIS group, the behavioural changes may be related to the sympatholytic action of ACE-inhibition. In this and a number of our previous experiments (Simko et al. 2009, 2015, 2017; Hrenak et al. 2013), ACE inhibition prominently reduced SBP but also exerted a number of protective effects on the cardiovascular system, supposedly via neurohumoral inhibition on various levels. ACE-inhibitors not only reduce angiotensin II formation, but also have a sympatholytic action via the attenuation of the release of norepinephrine from sympathetic nerve endings (Crozier et al. 1989, Simko and Simko 1999; Simko et al. 2003). This effect might be related to the reduced impulsivity along with normalization of the level of anxiety in SHR+LIS group. Since reduced level of anxiety in SHR may indicate the carelessness and uncritical exposure to the external dangerous impulses, the normalisation of anxiety by lisinopril might be considered behaviourally protective.

We conclude that lisinopril normalized the increase in SBP and partly reversed the alterations in anxiety-like behaviour in SHR.

Limitation. The limitation of the study is the lack of a lisinopril group. In the clinical setting, it is not usual to apply ACE-inhibition to healthy-normotensive patients, but the effect of lisinopril on the control group might mimic the situation, when a patient is inappropriately considered as hypertensive. Moreover, the possible behavioural alterations by lisinopril in normotensive rats might enable the identification of at-risk population regarding the increased potential for hypertension development.

Conflicts of interest. The authors declare that they have no conflicts of interest.

Acknowledgments. This work was supported by the following grants for scientific research: VEGA 1/0035/19, VEGA 2/0112/19.

\section{References}

Adriani W, Caprioli A, Granstrem O, Carli M, Laviola G (2003): The spontaneously hypertensive-rat as an animal model of ADHD: evidence for impulsive and non-impulsive subpopulations. Neurosci. Biobehav. Rev. 27, 639-651 https://doi.org/10.1016/j.neubiorev.2003.08.007

Aziriova S, Repova Bednarova K, Krajcirovicova K, Hrenak J, Rajkovicova R, Arendasova K, Kamodyova N, Celec P, Zorad S, Adamcova M, Paulis L, Simko F (2014): Doxorubicin-induced 
behavioral disturbances in rats: protective effect of melatonin and captopril. Pharmacol. Biochem. Behav. 124, 284-289 https://doi.org/10.1016/j.pbb.2014.06.021

Aziriova S, Repova K, Krajcirovicova K, Baka T, Zorad S, Mojto V, Slavkovsky P, Hodosy J, Adamcova M, Paulis L, Simko F (2016): Effect of ivabradine, captopril and melatonin on the behaviour of rats in L-nito-arginine methyl ester-induced hypertension. J. Physiol. Pharmacol. 67, 895-902

Bernatova I, Puzserova A, Dubovicky M (2010): Sex differences in social stress-induced pressor and behavioral responses in normotensive and prehypertensive rats. Gen. Physiol. Biophys. 29, 346-354 https://doi.org/10.4149/gpb_2010_04_346

Braszko JJ, Karwowska-Polecka W, Halicka D, Gard PR (2003): Captopril and enalapril improve cognition and depressed mood in hypertensive patients. J. Basic Clin. Physiol. Pharmacol. 14, 323-343 https://doi.org/10.1515/JBCPP.2003.14.4.323

Crozier IG, Teoh R, Kay R, Nicholls MG (1989): Sympathetic nervous system during converting enzyme inhibition. Am. J. Med. 87, 29S-32S https://doi.org/10.1016/S0002-9343(89)80925-8

Garcia A, Kirkpatrick K (2013): Impulsive choice behavior in four strains of rats: evaluation of possible models of AttentionDeficit/Hyperactivity Disorder. Behav. Brain Res. 238, 10-22 https://doi.org/10.1016/j.bbr.2012.10.017

Gentil L, Vasiliadis HM, Préville M, Berbiche D (2017): Impact of mental disorders on the association between adherence to antihypertensive agents and all-cause healthcare costs. J. Clin. Hypertens. (Greenwich) 19, 75-81 https://doi.org/10.1111/jch.12869

Germain L, Chouinard G (1989): Captopril treatment of major depression with serial measurements of blood cortisol concentrations. Biol. Psychiatry 25, 489-493 https://doi.org/10.1016/0006-3223(89)90203-5

Goldstein DS (1983): Plasma catecholamines and essential hypertension. An analytical review. Hypertension 5, 86-99 https://doi.org/10.1161/01.HYP.5.1.86

Hendley ED, Wessel DJ, Atwater DG, Gellis J, Whitehorn D, Low WC (1985): Age, sex and strain differences in activity and habituation in SHR and WKY rats. Physiol. Behav. 34, 379-383 https://doi.org/10.1016/0031-9384(85)90199-4

Hertzman M, Adler LW, Arling B, Kern M (2005): Lisinopril may augment antidepressant response. J. Clin. Psychopharmacol. 25, 618-620 https://doi.org/10.1097/01.jcp.0000186736.99523.1d

Howells FM, Bindewald L, Russell VA (2009): Cross-fostering does not alter the neurochemistry or behavior of spontaneously hypertensive rats. Behav. Brain Funct. 5, 24 https://doi.org/10.1186/1744-9081-5-24

Howells FM, Stein DJ, Russell VA (2012): Synergistic tonic and phasic activity of the locus coeruleus norepinephrine (LC-NE) arousal system is required for optimal attentional performance. Metab. Brain Dis. 27, 267-274 https://doi.org/10.1007/s11011-012-9287-9

Hrenak J, Arendasova K, Rajkovicova R, Aziriova S, Repova K, Krajcirovicova K, Celec P, Kamodyova N, Barta A, Adamcova M, Paulis L, Simko F (2013): Protective effect of captopril, olm- esartan, melatonin and compound 21 on doxorubicin-induced nephrotoxicity in rats. Physiol. Res. 62 (Suppl. 1), S181-189

Kishikawa Y, Kawahara Y, Yamada M, Kaneko F, Kawahara H, Nishi A (2014): The spontaneously hypertensive rat/Izm (SHR/Izm) shows attention deficit/hyperactivity disorderlike behaviors but without impulsive behavior: therapeutic implications of low-dose methylphenidate. Behav. Brain Res. 274, 235-242 https://doi.org/10.1016/j.bbr.2014.08.026

Krajcirovicova K, Aziriova S, Baka T, Repova K, Adamcova M, Paulis L, Simko F (2018): Ivabradine does not impair anxiety-like behavior and memory in both healthy and L-NAME-induced hypertensive rats. Physiol. Res. 67, S655-S664

Mc Fie S, Sterley T-L, Howells FM, Russell VA (2012): Clozapine decreases exploratory activity and increases anxiety-like behaviour in the Wistar-Kyoto rat but not the spontaneously hypertensive rat model of attention-deficit/hyperactivity disorder. Brain Res. 1467, 91-103 https://doi.org/10.1016/j.brainres.2012.05.047

Olexova L, Stefanik P, Krskova L (2016): Increased anxiety-like behaviour and altered GABAergic system in the amygdala and cerebellum of VPA rats - An animal model of autism. Neurosci. Lett. 629, 9-14 https://doi.org/10.1016/j.neulet.2016.06.035

Paulis L, Foulquier S, Namsolleck P, Recarti C, Steckelings UM, Unger T (2016): Combined angiotensin receptor modulation in the management of cardio-metabolic disorders. Drugs 76, 1-12 https://doi.org/10.1007/s40265-015-0509-4

Pechanova O, Jendekova L, Kojsova S, Jagla F (2006): Possible role of nitric oxide in the locomotor activity of hypertensive rats. Behav. Brain Res. 174, 160-166 https://doi.org/10.1016/j.bbr.2006.07.021

Peres FF, Eufrasio RA, Gouvea DA, Diana MC, Santos CM, Swardfager W, Abilio VC, Cogo-Moreira H (2018): A schizophrenialike behavioral trait in the SHR model: Applying confirmatory factor analysis as a new statistical tool. Prog. Neuropsychopharmacol. Biol. Psychiatry 85, 16-22 https://doi.org/10.1016/j.pnpbp.2018.03.021

Pokusa M, Hlavacova N, Csanova A, Franklin M, Zorad S, Jezova D (2016): Adipogenesis and aldosterone: a study in lean tryptophan-depleted rats. Gen. Physiol. Biophys. 35, 379-386 https://doi.org/10.4149/gpb_2016020

Puzserova A, Torok J, Sotnikova R, Zemancikova A, Bernatova I (2012): Reactivity of the mesenteric bed arteries of normotensive rats exposed to chronic social stress. Gen. Physiol. Biophys. 31, 279-290

https://doi.org/10.4149/gpb_2012_032

Repova K, Krajcirovicova K, Mullerova M, Aziriova S, Baka T, Zorad S, Slavkovsky P, Hodosy J, Celec P, Adamcova M, Paulisi L, Simko F (2018): Effect of melatonin on the behaviour of rats with continuous light-induced hypertension. Gen. Physiol. Biophys. 37, 469-473

https://doi.org/10.4149/gpb_2017061

Santos CM, Peres FF, Diana MC, Justi V, Suiama MA, Santana MG, Abílio VC (2016): Peripubertal exposure to environmental enrichment prevents schizophrenia-like behaviors in the SHR strain animal model. Schizophr. Res. 176, 552-559 https://doi.org/10.1016/j.schres.2016.06.006 
Senko T, Svitok P, Krskova L (2017): Effect of maternal renin-angiotensin-aldosterone system activation on social coping strategies and gene expression of oxytocin and vasopressin in the brain of rat offspring in adulthood. Gen. Physiol. Biophys. 36, 391-398 https://doi.org/10.4149/gpb_2017013

Shields GS, Slavich GM (2017): Lifetime Stress Exposure and Health: A review of contemporary assessment methods and biological mechanisms. Soc. Personal. Psychol. Compass 11, e12335 https://doi.org/10.1111/spc3.12335

Simko F, Simko J (1999): Heart failure and angiotensin converting enzyme inhibition: problems and perspectives. Physiol. Res. 48, 1-8

Simko F, Simko J, Fabryova M (2003): ACE-inhibition and angiotensin II receptor blockers in chronic heart failure: pathophysiological consideration of the unresolved battle. Cardiovasc. Drugs Ther. 17, 287-290 https://doi.org/10.1023/A:1026215712983

Simko F, Pechanova O, Pelouch V, Krajcirovicova K, Mullerova M, Bednarova K, Adamcova M, Paulis L (2009): Effect of melatonin, captopril, spironolactone and simvastatin on blood pressure and left ventricular remodelling in spontaneously hypertensive rats. J. Hypertens. Suppl. 27, S5-10 https://doi.org/10.1097/01.hjh.0000358830.95439.e8

Simko F, Pechanova O, Krajcirovicova K, Matuskova J, Pelouch V, Adamcova M, Paulis L (2015): Effects of captopril, spironol- actone, and simvastatin on the cardiovascular system of nondiseased Wistar rats. Int. J. Cardiol. 190, 128-130 https://doi.org/10.1016/j.ijcard.2015.04.092

Simko F, Pechanova O, Repova K, Aziriova S, Krajcirovicova K, Celec P, Tothova L, Vrankova S, Balazova L, Zorad S, Adamcova M (2017): Lactacystin-induced model of hypertension in rats: effects of melatonin and captopril. Int. J. Mol. Sci. 18, E1612 https://doi.org/10.3390/ijms18081612

Srinivasan J, Suresh B, Ramanathan M (2003): Differential anxiolytic effect of enalapril and losartan in normotensive and renal hypertensive rats. Physiol. Behav. 78, 585-591 https://doi.org/10.1016/S0031-9384(03)00036-2

Tsai M-L, Kozlowska A, Li Y-S, Shen W-L, Huang ACW (2017): Social factors affect motor and anxiety behaviors in the animal model of attention-deficit hyperactivity disorders: A housingstyle factor. Psychiatry Res. 254, 290-300 https://doi.org/10.1016/j.psychres.2017.05.008

Vilchinsky N, Ginzburg K, Fait K, Foa EB (2017): Cardiac-diseaseinduced PTSD (CDI-PTSD): A systematic review. Clin. Psychol. Rev. 55, 92-106 https://doi.org/10.1016/j.cpr.2017.04.009

Received: January 17, 2019

Final version accepted: March 18, 2019 